\title{
Synthetic and NMR spectroscopic investigations of fulvenes and fulvalenes
}

\author{
Markus Neuenschwander \\ Institut für Organische Chemie, Universität Bern, CH-3012 Bern \\ (Switzerland)
}

\begin{abstract}
Synthetic concepts for triafulvenes and nonafulvenes are discussed, and a new synthesis of fulvalenes consisting in an oxidative coupling of $(4 \mathrm{n}+2) \pi$ anions by $\mathrm{Ag}^{+}$or $\mathrm{Cu}^{2+}$ is outlined. This sequence has allowed the synthesis of parent pentafulvalene 10 , nonapentafulvalene 14 , and nonafulvalene 12 . NMR investigations of pentafulvenes 2 show that systematic substituent effects that influence bond lengths are observed in terms of changes of vicinal $\mathrm{H}, \mathrm{H}$ coupling constants, so that the extent of $\pi$-delocalisation in the five membered ring may be estimated. On the other hand, changes in charge density are available from changes in $13_{C}$ chemical shifts, provided that steric effects are small. NMR approaches for explaining the surprisingly different spectroscopic behaviour of nonafulvenes $\underline{4 \mathrm{k}}$ and $\underline{4 \mathrm{a}}$ are presented.
\end{abstract}

\section{INTRODUCTION}

Fulvenes and fulvalenes have intrigued experimental and theoretical chemists for more than four decades. During this time, several fundamental questions concerning these molecules such as typical reactivity, general spectroscopic properties, and aromaticity - have been roughly answered (ref. 1). However, more detailed information about these fascinating molecules was not available because some of the most important parent systems (urgently needed as reference compounds for spectroscopic purposes) were missing even up to a few years ago. In this contribution some general synthetic concepts for parent fulvenes and fulvalenes will be discussed, and a NMR investigation revealing systematic substituent effects will be presented.

\section{Scheme 1}<smiles>C=C1C=C1</smiles><smiles>C=C1C=CC=C1</smiles>

1

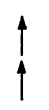

色

5

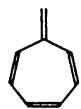

3
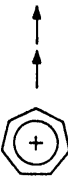

7

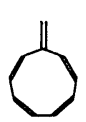

4
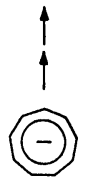

8

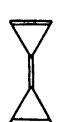

9

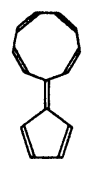

14

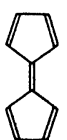

10

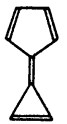

15

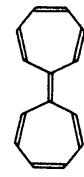

11

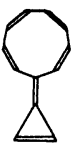

16

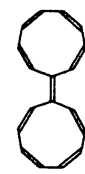

12

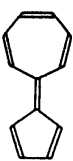

17

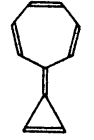

13

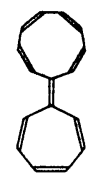

Fulvenes are cyclic cross conjugated molecules with an odd number of $\mathrm{C}$ atoms in the ring. According to the size of the ring skeleton they are named triafulvenes 1 , pentafulvenes 2 , heptafulvenes 3 and nonafulvenes 4 . Spectroscopic investigations show that most of the parent compounds of this family are characterised by the lack of a diamagnetic ring current, strongly alternating bond lengths and a comparably low dipole moment. For instance, the chemical shifts of the ring protons of pentafulvene $\underline{2}$ (ref. 2 ; synthesis: ref. 3) heptafulvene 3 (refs. 4, 5) and nonafulvene $\underline{4}$ (ref. 6) are very similar to those of cyclopentadiene, cycloheptatriene and cyclononatetraene; and the vicinal $\mathrm{H}, \mathrm{H}$ coupling constants of pentafulvene alternate in a typical way (ref. 2). Furthermore, microwave spectroscopy shows that the dipole moments of $2 \underline{2}(\mu=0.44 \mathrm{D}$, ref. 7) and $\underline{3}(\mu=0.48 \mathrm{D}$, ref. 8) are small. Significant contributions of dipolar resonance forms to the ground state seem to exist only for triafulvene 1 according to recent NMR results (refs. 9, 10). Because of these facts most fulvenes have to be classified as typical non-aromatic compounds with rather olefinic properties. In fact, thermal stability of the parent systems is extremely low. While triafulvene (refs. 9, 10) 
and heptafulvene (ref. 4) polymerise very easily at $-20^{\circ}$, pentafulvene undergoes an easy Diels-Alder dimerisation reaction (ref. 1l), while the stability of nonafulvene is dramatically reduced by its easy valence isomerisation to dihydro-benzofulvene (ref. 6). Fortunately these unstable parent compounds are stabilised by introduction of appropriate substituents at the exocyclic C-atom, namely $\underline{1}$ and $\underline{3}$ by electron-accepting groups, while $\underline{2}$ and $\underline{4}$ are stabilised by electron-donating groups. A qualitative rule states that fulvenes are electronically stabilised by substituents favouring $\pi$-delocalisation in the ring.

Fulvalenes are cyclic cross conjugated molecules with two fully conjugated rings which are connected by a central double bond. If all combinations between three to nine membered rings are considered, then fulvalenes with two identical rings (9-12), fulvalenes with rings of similar electron demand $(13,14)$ and fulvalenes with rings of inverse electron demand (15-18) may be distinguished. Of all the parent systems $9-18$ so far only heptafulvalene 11 (ref. 12) and heptapentafulvalene 17 (ref. 13) have been isolated and characterised. The UV spectra of very dilute solutions $(\overline{10}-3 \mathrm{M})$ of pentafulvalene 10 (ref. 14) have been recorded and a proton NMR signal at $6.47 \mathrm{ppm}\left(\mathrm{d}_{8}-\mathrm{THF},-60^{\circ}\right)$ has been mentioned (ref. 15). All the other parent systems have been unknown so far, although some highly substituted and/or electronically stabilised fulvalenes of types 10-18 have been prepared. (For some leading references see refs. $16-20$ ).

\section{SYNTHESIS OF FULVENES AND FULVALENES}

\section{General remarks}

There exist a considerable number of fulvene syntheses. In most cases the corresponding Hückel-type cations and anions are applied (Scheme 1). Obviously, in principle similar sequences may be applied for triafulvenes $\underline{1}$ and heptafulvenes $\underline{3}$ starting with cations $\underline{5}$ and $\underline{7}$. However, since hydride abstraction from the intermediary cyclopropenes and cycloheptatrienes is not easy, alternative pathways start with substituted cyclopropenylium as well as tropylium-salts bearing potential leaving groups. On the other hand, successful procedures for pentafulvenes $(\underline{6} \rightarrow \underline{2})$ have a good chance for nonafulvenes as well $(\underline{8} \longrightarrow \underline{4})$.

The general scheme consisting in reactions of cyclic cations $\underline{5}$ and 7 with cyclic anions 6 and $\underline{8}$ seems to be very attractive for fulvalenes $15-18$ with rings of inverse electron demand. It has been successfully applied for highly substituted fulvalenes (refs. 16-20) but seems to fail for the parent systems 15-18 (ref. 21) due to problems with hydride abstraction. The alternative pathway starting with substituted tropylium salts has been applied to the synthesis of heptapentafulvalene 17 (ref. 5).

\section{Synthetic concepts for triafulvene 1}

With respect to the highly strained triafulvene 1 , several synthetic concepts may be envisaged. From what has been said before, it is not surprising that the most straightforward plan - reaction of cyclopropenylium salts with methyllithium, followed by hydride abstraction has not been realised so far. However, substituted cyclopropenylium salts of type $19\left(R^{1}, R^{2}\right.$ = alkyl or phenyl) bearing a potential leaving group $\mathrm{X}$ are easily prepared by acylation or alkylation of substituted cyclopropenones. In fact, the first synthesis of stabilised triafulvenes (ref. 22) used a substituted cyclopropenone as starting material which was reacted with an acidic methylene compound (e.g. malodinitrile) in the presence of acetic anhydride. However, the sequence failed for triafulvene $\underline{1}$ because methyllithium attacked precursors 19 at the least hindered position so that the potential leaving group irreversibly ended up in vinylic position (ref. 23).

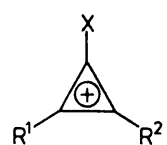

19

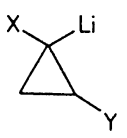

20

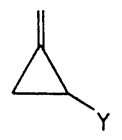

21

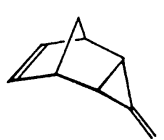

22

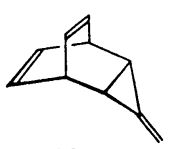

23

Some years ago, we showed trifunctional cyclopropanes to be attractive precursors of triafulvene: metalation by means of a halogen-lithium exchange gives the carbenoid 20 which is methylated at $-80^{\circ}$. Subsequent elimination of the leaving groups $x$ (to give intermediate 21 with $\mathrm{Y}=\mathrm{SC}_{6} \mathrm{H}_{5}$ ) and $\mathrm{Y}$ gives triafulvene 1 which has been trapped as cycloaddition product $\frac{22}{2}$ (ref. 24).

Very recently direct spectroscopic evidence for the parent system $\underline{I}$ has been obtained by Billups (ref. 9) and Staley (ref. 10) who eliminated $\mathrm{HCl}$ and $\mathrm{HBr}$ from precursors 2l ( $\mathrm{X}=\mathrm{Cl}$, $\mathrm{Br}$ ) prepared by carbene addition to allene. 
Although triafulvene $\underline{I}$ is now available, another general concept for the synthesis of unstable fulvenes and fulvalenes consists in retro-Diels-Alder reactions that produce aromatic systems such as benzene or naphthalene besides triafulvene. Attractive precursors 23 for that plan (which has successfully been applied to cyclopropenes (ref. 25)) may be prepared by carbene addition to barrelene or benzo-barrelene (ref. 26).

\section{Synthesis of nonafulvenes}

General remarks. Nonafulvenes would not have been available without the spectacular synthesis of cyclononatetraenide 8 realised by Katz and Garratt (ref. 27) as well as by LaLancette and Benson (ref. 28). Later on, careful investigations by Boche (ref. 29) showed that alkali metals react with 9-anti-chloro- or 9-anti-methoxy-bicyclo[6.1.0]nona-2,4,6-triene predominantly or exclusively to give cis,cis,cis,trans-cyclononatetraenide 24 (ccct-CNT ${ }^{-}$), which then isomerises to all-cis-cyclononatetraenide 8 ( $\mathrm{CNT}^{-}$) (ref. 30). Under carefully controlled conditions, pure solutions of both anions $\underline{8}$ and $\underline{24}$ may be obtained.

\section{Scheme 2}<smiles>CC(O[Na])=C1CCCCC1</smiles>

26<smiles>CC(=O)OC(C)=C1CCCCC1</smiles>

$4 \mathrm{~b}$
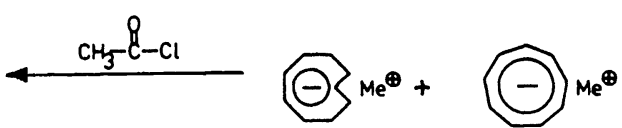

8

24

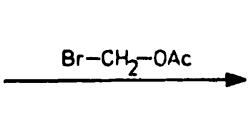

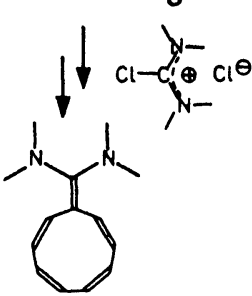

$4 k$

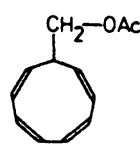

$25 a$<smiles>COCCO</smiles><smiles></smiles>

$4 a$

The first non-annelated nonafulvene $4 \mathrm{k}$ was prepared by Hafner and Tappe in 1969 (ref. 31). Reaction of chloro-formamidinium chloride with cyclononatetraenide gave 10,10-bis (dimethylamino) nonafulvene $4 \mathrm{k}$ in a low yield. In 1974 we isolated the electronically undisturbed parent system $4 \mathrm{a}$ (ref. 6): nucleophilic substitution of bromomethyl-acetate with $\mathrm{CNT}^{-}$gives acetoxymethyl-cyclononatetraene 25 , and the unstable nonafulvene $\underline{4 a}$ is isolated after elimination of acetic acid from 25 with strong bases. In 1978 Boche showed that CNT is easily acylated to give nonafulvenolates 26 which are predominantly 0-acylated or silylated by another equivalent of electrophile (ref. 32). In this way, a series of new nonafulvenes including $4 \mathrm{~b}$ has been prepared (ref. 33).

Synthesis of new nonafulvenes (ref. 34). Seeking an explanation for the surprisingly different spectroscopic behaviour of nonafulvenes $\underline{4 a}$ and $\underline{4 k}$ (cf. later), we attempted the realisation of a synthetic link between the two compounds by preparing a series of nonafulvenes of increasing electron-donating capacity. However, it turned out that nonafulvenes $\underline{4}$ are not as easily prepared as pentafulvenes 2 . One serious problem arises from the easy valence isomerisation of both cyclononatetraenes 25 and nonafulvenes $\underline{4}$ which affords reaction temperatures below $-20^{\circ}$. Furthermore $\mathrm{CNT}^{-} 8$ is less nucleophilic than cyclopentadienide 6 . Fortunately with anions 8 and 24 two nucleophiles are available, of which ccct-CNT ${ }^{-} 24$ turns out to be more nucleophilic than 8 . However, different reaction products have to be expected depending on the site of attack of the electrophile (ref. 35); and only electrophilic attack at C(1) of $\underline{24}$ gives the desired all-cis-cyclononatetraenes 25 . Unfortunately, preparative problems are dramatically increased by the low acidity of cyclononatetraenes 25 . Combined with steric shielding of $\mathrm{C}(1)$, deprotonation of cyclononatetraenes 25 is very troublesome. Finally, 1,5 proton shifts do not help as they are too slow at $-20^{\circ}$.

\section{Scheme 3}

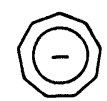

$\mathrm{Me}^{\oplus}$

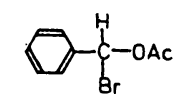

or

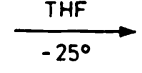

8

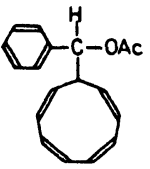

25 c : $65 \%$
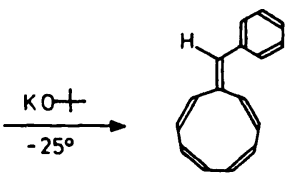

4c : $24 \%$

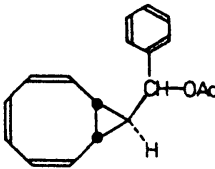

27c 
Reaction of cyclononatetraenides $\underline{8}$ or 24 with l-bromo-alkylacetates or bromo-benzylacetates seems to be an attractive sequence for nonafulvenes: this versatile method for the synthesis of pentafulvenes (ref. 36) has been applied to the synthesis of the parent system $4 a$ (ref. 6). However, application is limited by the comparably slow rate of formation of l-acetoxymethyland $\alpha$-acetoxybenzyl-cyclononatetraenes 25 , furthermore deprotonation of cyclononatetraenes 25 proves to be difficult. Apart from 4a only 10-phenyl-nonafulvene 4c has been prepared by this method. Attempts to increase the nucleophilic character of the $1 \overrightarrow{0 \pi}-$ anion by reacting ccct-CNT ${ }^{-} 24$ with $\alpha$-bromobenzyl-acetate give the bicyclic triene $27 \mathrm{c}$ in a high yield. Products of this type (ref. 37) are easily explained by assuming an electrophilic attack at C(4) to $\mathrm{C}(7)$ of anion 24 , followed by valence isomerisation and Cope-rearrangement (ref. 35).

Scheme 4
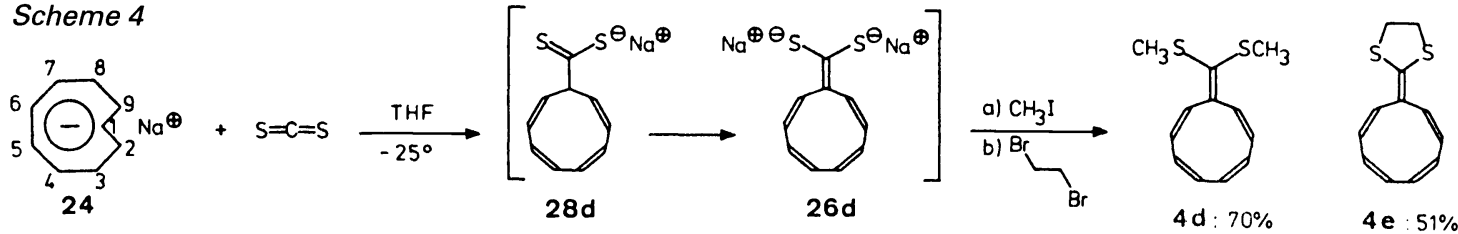

Acylation of cyclononatetraenides, as applied for the first time by Boche (ref. 32) has several advantages: e.g. CCCt-CNT- seems to react predominantly with $\mathrm{C}-1$ if added to small electrophiles like $\mathrm{CS}_{2}$ as well as in $\mathrm{S}_{N_{1}}$-type reactions of stabilised carbenium ions (like methylated $\mathrm{CS}_{2}$ ); also, the acidity of the cyclononatetraene intermediate of type 28 is increased, thus facilitating deprotonation. This sequence was successfully applied to nonafulvenes $\underline{4 \mathrm{~d}}$ and $\underline{4 \mathrm{e}}$.

\section{Scheme 5}

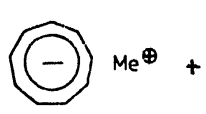

8<smiles>CN(C)C(=S)Cl</smiles>

291

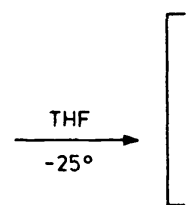

L
25

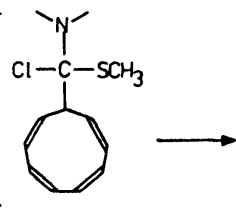

i

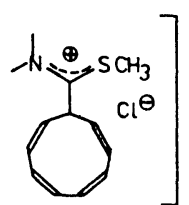

$30 \mathrm{i}$

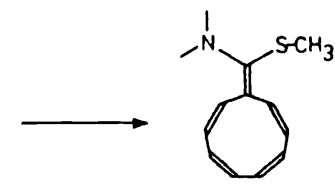

$4 \mathbf{i}: 41 \%$

Similarly prepared: $\left.4 f\left(R^{1}=\mathrm{OCH}_{3}, \mathrm{R}^{2}=\mathrm{H}\right) ; 4 \mathrm{~g}\left(\mathrm{R}^{1}=\mathrm{R}^{2}=\mathrm{OCH}\right)_{3} ; 4 \mathrm{~h}\left(\mathrm{R}^{1}, \mathrm{R}^{2}=\mathrm{O}-\mathrm{CH}_{2}-\mathrm{CH}_{2} \mathrm{O}\right) ; 4 \mathrm{~J}\left(\mathrm{R}^{1}=\mathrm{N}_{2} \mathrm{C}_{2} \mathrm{H}_{5}\right)_{2}, \mathrm{R}^{2}=\mathrm{N}\left(\mathrm{CH}_{3}\right)_{2}\right)$

Reaction of cyclononatetraenides with electronically stabilised carbenium ions - as applied by Hafner and Tappe (ref. 31) - seems to be a simple and straightforward synthetic route for nonafulvenes. It has to be mentioned, however, that sterically hindered as well as electronically stabilised carbenium ions 29 need ccct-CNT ${ }^{-}$which predominantly reacts with $\mathrm{C}(1)$. Furthermore, if carbenium ions bearing strongly electron releasing substituents are applied, nonafulvenes $\underline{4}$ are formed in a simple one-pot procedure (although deprotonation of cyclononatetraenes 25 is not easy). In such cases, the sequence $25 i \longrightarrow 30 i \longrightarrow 4 i$ is the most reasonable pathway; an intermediary of type 30 has been isolated (ref. 38$)$.

\section{Synthesis of fulvalenes by oxidative coupling of $(4 n+2) \pi$-anions}

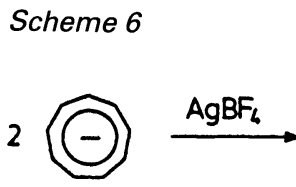

8

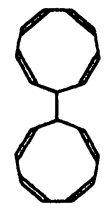

31

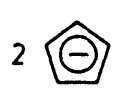

6

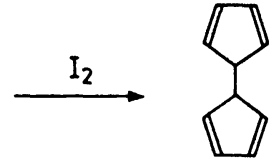

32

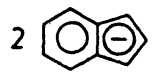

33

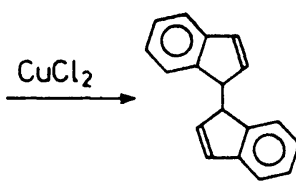

34

In the course of our nonafulvene experiments, we accidentally discovered that oxidative coupling of cyclononatetraenide with $\mathrm{AgBF}_{4}$ gave dihydro-nonafulvalene 31 in a nearly quantitative yield (ref. 39). Some reactions of this type had been previously reported in the literature: cyclopentadienide 6 may be reacted with iodine to give dihydro-pentafulvalene 32 in a undisclosed yield (ref. 14). After deprotonation and bubbling oxygen through the very dilute solution, a colour change to red indicated the formation of pentafulvalene 10. Treatment of indenide 33 with $\mathrm{CuCl}_{2}$ gave 1,1'-bis(indenyl) 34 in a $95 \%$ yield (ref. 40). Application of Doering's procedure to cyclononatetraenide allowed Hafner and co-workers (ref. 4l) to isolate dihydro-nonafulvalene 31 in a 30 yield and to prepare di- and tetra-t-butyl-pentafulvalenes (ref. 15).

So far, our accidentally-discovered coupling reaction has allowed a considerable improvement of the yield of dihydro-nonafulvalene $\underline{31}$. However, as formulated for $\underline{10}$, the sequence $\underline{6} \longrightarrow \underline{32}$ $\longrightarrow 35 \longrightarrow 10$ could be developed into a very general and attractive synthesis of fulvalenes the most attractive targets being the so far nearly unknown pentafulvalene 10 and the unknown 
parent systems nonafulvalene 12 and nonapentafulvalene 14. Coupling of two "Hückel"-anions by means of $\mathrm{Ag}^{+}$or $\mathrm{Cu}^{2+}$ would give the dihydrofulvalene, while another twofold deprotonation and a second treatment with $\mathrm{Ag}^{+}$or $\mathrm{Cu}^{2+}$ (which has never been realised so far) would afford the appropriate fulvalene.

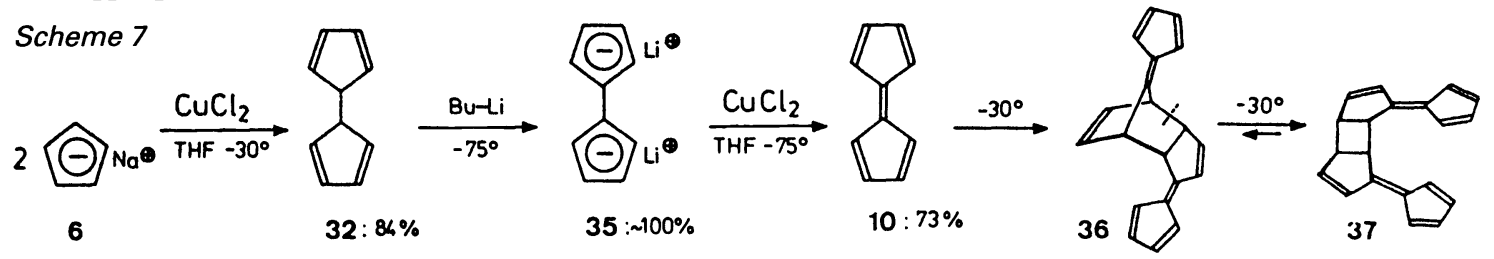

In fact, cyclopentadienide may be coupled in the presence of $\mathrm{Cu}^{2+}$ (which is preferable to $\mathrm{Ag}^{+}$ in this case) to give dihydrofulvalene 32 in a high yield. After filtration from the colourless precipitate of $\mathrm{CuCl}$, deprotonation proceeds nearly quantitatively, and another treatment with $\mathrm{CuCl}_{2}$ and concentration gives $0.3-\mathrm{M}$ red solutions of spectroscopically pure pentafulvalene 10 (ref. 42). As Doering noted in 1959, pentafulvalene 10 is, in fact, a very reactive compound. It is much more unstable than pentafulvene $\underline{2}$, as it polymerises very easily in the presence of traces of acid, and it dimerises in concentrated solutions to give an unstable Diels-Alder product 36 which rearranges to the formal [2+2]-cycloaddition product 37 . The same type of rearrangement has been observed for dimers of cyclopentadienone (ref. 43 ) and pentafulvene 2 (ref. 11 ).

The structure of pentafulvalene 10 follows from spectroscopic evidence. The UV spectrum of 10 is very similar to that of 6-vinyl-pentafulvenes. Compared to 40 , the intense absorption near $300 \mathrm{~nm}$ shows more vibrational fine structure and is slightly shifted to shorter wavelengths (with maxima at 277, 287, 299 and $313 \mathrm{~nm}$ ). On the other hand, the broad band of low intensity undergoes a bathochromic shift from $386(\underline{40})$ to $420 \mathrm{~nm}(\underline{10})$ in $\mathrm{n}$-hexane. In the $1_{\mathrm{H}} \mathrm{NMR}$ spectrum in $\mathrm{CD}_{2} \mathrm{Cl}_{2}$, complex multiplets are centered at 6.69 and $6.59 \mathrm{ppm}$. The size of vicinal $\mathrm{H}, \mathrm{H}$ coupling constants $\left(\mathrm{J}_{1}, 2=5.41 ; \mathrm{J}_{2}, 3=1.99 \mathrm{~Hz}\right)$ demonstrates that the $\pi$-system is highly localised.

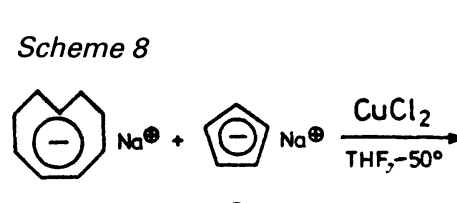

24

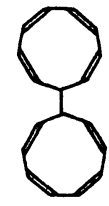

31

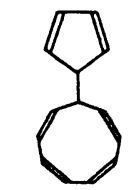

38

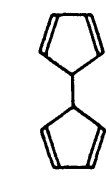

32

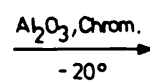

$-20^{\circ}$

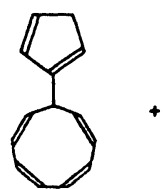

39

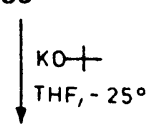

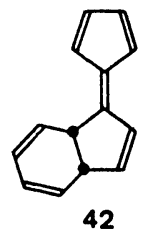
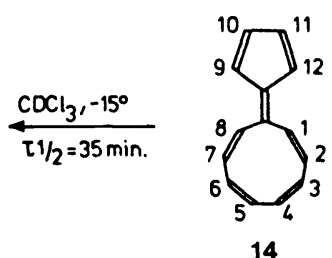
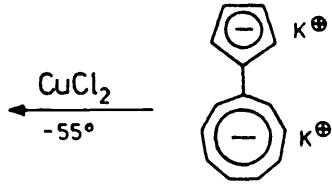

41

Application of the sequence to nonapentafulvalene 14 affords a coupling of a $1: 1$ mixture of anions 6 and 8 or 24 . Due to the fact that mixtures of three dihydrofulvalenes 31,38 and 32 are expected and obtained in a ratio $1: 5: 4$, separation problems arise. If a $5: 1$ excess of anions $\underline{6}: 24$ is applied, then dihydrofulvalene $\underline{31}$ is suppressed. Treatment of the obtained 1:5 mixture of compounds 38 and 32 with aluminium oxide (basic I) gives a separable mixture of 39 and 40 . Twofold deprotonation $39 \rightarrow 41$ is realised with potassium-t-butoxide, whereupon the dipotassium salt 41 precipitates. Low temperature reaction with $\mathrm{CuCl}_{2}$ affords a red suspension which is worked up at $-50^{\circ}$ by chromatography and evaporation of the solvent to yield concentrated solutions of the so far unknown nonapentafulvalene 14 (ref. 44).

The structure of the new fulvalene 14 is proved by its spectra as well as by its very fast cyclisation to 3,4-dihydro-benzopentafulvalene 42 . In the proton NMR spectrum (360 $\mathrm{MHz}$, $\mathrm{d}_{6}$-acetone, $\left.-40^{\circ}\right)$ the ring protons are pairwise equivalent $(\mathrm{H}(1) / \mathrm{H}(8) 6.82 ; \mathrm{H}(2) / \mathrm{H}(7) 6.08$; $\mathrm{H}(3) / \mathrm{H}(6) 6.13 ; \mathrm{H}(4) / \mathrm{H}(5) 5.96 ; \mathrm{H}(9) / \mathrm{H}(12) 6.57 ; \mathrm{H}(10) / \mathrm{H}(11) 6.43 \mathrm{ppm})$. The vicinal proton coupling constants are $5.30 \mathrm{~Hz}$ for $\mathrm{J}_{9,10}=\mathrm{J}_{11,12}$ and $2.10 \mathrm{~Hz}$ for $\mathrm{J}_{10,11}$ showing that the $\pi$-system is highly localised. The $13 \mathrm{C}$ chemical shifts of C-atoms C(9) - C(12) (C(9)/C(12) 121.2; C(10/C(11) $132.2 \mathrm{ppm})$ are close to those of non-polar pentafulvenes, those of C-atoms $C(1)-C(8)(133.0,129.5,128.5,128.0 \mathrm{ppm})$ are similar to those of non-polar nonafulvenes, thus supporting a highly localised $\pi$-system for 14 . 


\section{Scheme 9}

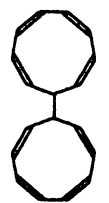

31

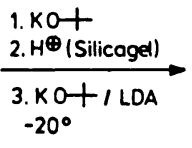

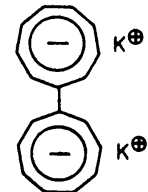

43

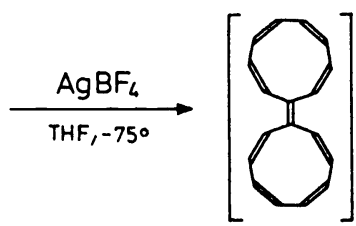

12

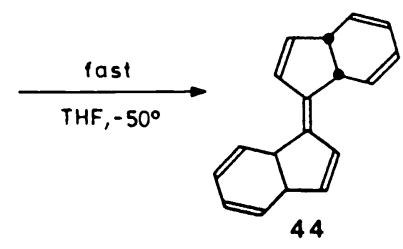

+3 diastereomeric products

According to Scheme 9, nonafulvalene 12 should be easily accessible by our method. However, one has to bear in mind that deprotonation of sterically hindered cyclononatetraenes is extremely difficult. With several strong bases only 1 proton of 31 is removed so that oxidative coupling of two mono-anions gives tetrameric products. Fortunately a deprotonation/protonation equilibrium is obtained with potassium-t-butoxide so that sp 3 -atoms are shifted to the periphery of the rings. Following this, potassium-t-butoxide/LDA is strong enough for twofold deprotonation to take place giving the dianion 43 . Oxidative coupling proceeds very easily in the presence of $\mathrm{Ag}^{+}$(even at -750) to yield nonafulvalene 12 (ref. 45).

Compared to fulvalenes 10,14 and 17, nonafulvalene 12 is the most unstable parent system. Even at $-50^{\circ}$ valence isomerisation proceeds very easily to give a mixture of 4 diastereomeric tetrahydro-dibenzopentafulvalenes. Because of this fast process, direct spectroscopic evidence for 12 is so far incomplete, whereas the structure of E-anti-isomer 44 has been proved by both spectroscopic methods and an X-ray analysis.

\section{NMR SPECTROSCOPIC INVESTIGATION OF FULVENES AND FULVALENES}

According to spectroscopic investigations most parent fulvenes and fulvalenes are non-aromatic compounds with strongly alternating bond lengths, a low dipole moment, and no significant diamagnetic ring current. This is shown by the microwave spectra of pentafulvene $\underline{2}$ (ref. 7) and heptafulvene $\underline{3}$ (ref. 8) and confirmed by the proton and ${ }^{13} \mathrm{C}$ NMR spectra of $\underline{2}$ (ref. 2), $\underline{3}$ (ref. 46), $\underline{4}$ (ref. 6), 10 and 14 (this work) as well as 17 (ref. 46). On the other hand, rare X-ray data of pentafulvenes show that electron donating groups at $\mathrm{C}(6) \mathrm{re-}$ duce alternation of bond lengths (ref. 47), and the same is true for electron-accepting substituents placed at the exocyclic c-atom of heptafulvenes (ref. 48).

Obviously, the experimental fulvene chemist would be glad to have at his disposal a simple criterion which would allow him to estimate the extent of $\pi$-delocalisation or aromaticity. This is especially true for the parent fulvenes and fulvalenes that are much too unstable for $X$-ray investigation. Although the NMR spectra of a series of fulvenes and fulvalenes have been discussed (refs. 2, 49) only very qualitative conclusions with respect to $\pi$-delocalisation and charge density distribution have been drawn.

Because the planar $\pi$-system of pentafulvenes is very attractive for the investigation of electronic substituent effects in cross-conjugated molecules, we decided to look at the high-field proton and ${ }^{13} \mathrm{C}$ NMR spectra of two classes of pentafulvenes. In p-X-phenyl-pentafulvenes $2 \mathrm{~A}$ the substituent $\mathrm{X}$ is separated from the fulvene ring by a phenyl ring as spacer so that steric effects of substituents $X$ should be small. In pentafulvenes $2 B$ bearing substituents directly at $C(6)$ steric effects can be reduced by bridging the exocyclic substituents in a five membered ring. The long term objective was an evaluation of the extent of $\pi$-delocalisation in parent pentafulvalenes $10,14,15$ and 17 as well as the investigation of non-planar nonafulvenes $\underline{4}$.

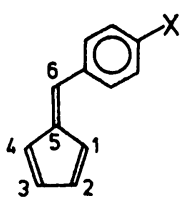

2A

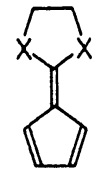

$2 B$

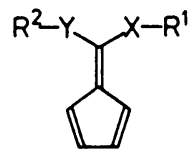

$2 \mathrm{C}$

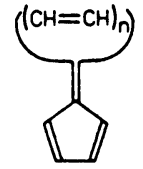

$n=2: 10$

$n=3: 17$

$n=4: 14$

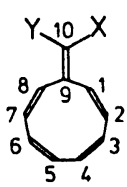

4

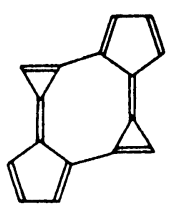

45

\section{Substituent effects on NMR parameters of pentafulvenes}

High-field NMR spectra of a series of 6-( $\mathrm{p}$-X-phenyl)pentafulvenes $2 \mathrm{~A}$ and of 6 -monosubstituted and 6,6-disubstituted pentafulvenes of type $\underline{2 \mathrm{~B}}$ and $\underline{2 \mathrm{C}}$ have been analysed, and $1_{\mathrm{H}}$ as well as 13C NMR parameters have been determined (ref. 50). Substituents were varied from electron accepting groups $\left(\mathrm{X}=\mathrm{NO}_{2}\right)$ to electron donating groups $\left(\mathrm{X}=\mathrm{NMe}_{2}\right)$ in pentafulvenes $2 \mathrm{~A}$, and from weakly electron releasing $(\mathrm{X}=\mathrm{a} / \mathrm{kyl})$ to strongly electron releasing groups ( $\mathrm{X}=\mathrm{NMe} 2$ ) in penta- 


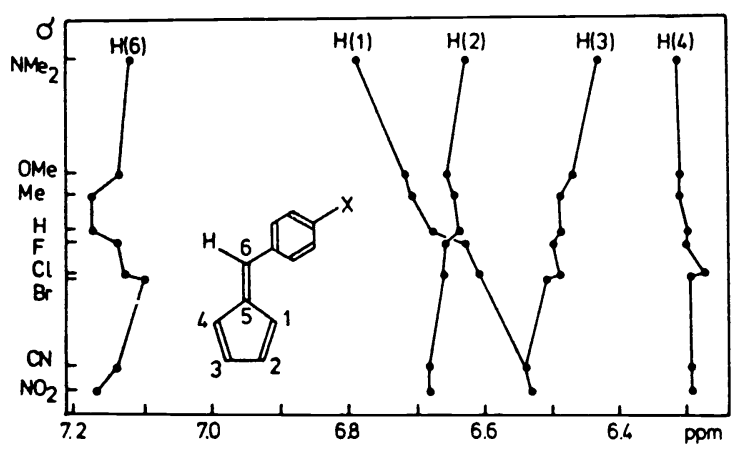

Fig. 1. Substituent effects on $1_{\mathrm{H}}$ chemical shifts of pentafulvenes $2 \mathrm{~A}$.

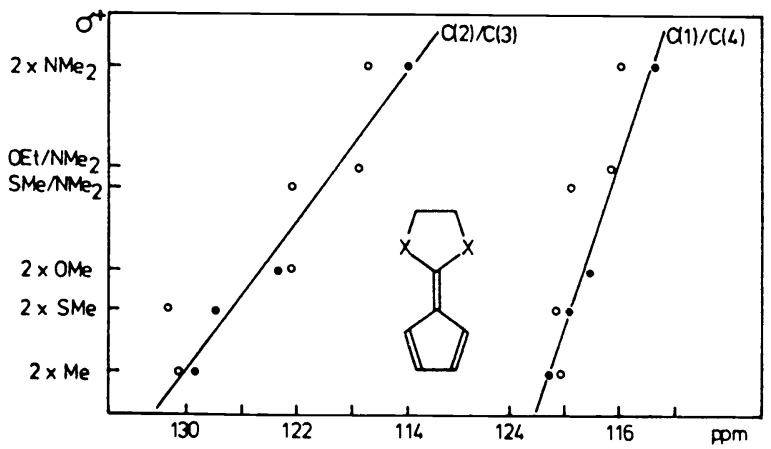

Fig. 2. Substituent effects on ${ }^{13} \mathrm{C}$ chemical shifts of pentafulvenes $2 \mathrm{~B}(\bullet)$ and $2 \mathrm{C}(0)$.

fulvenes $2 \mathrm{~B}$ and $\underline{2 \mathrm{C}}$. In the following diagrams, Hammett substituent constants $\sigma \mathrm{p}$ or $\sigma \mathrm{p}^{+}$are taken as a measure of the substituent effect and are plotted against the appropriate NMR parameter.

Proton chemical shifts. According to Fig. l, no linear correlations between substituent constants $\sigma_{\mathrm{p}}^{+}$and proton chemical shifts are observed even in sterically very similar pentafulvenes of type $2 \mathrm{~A}$, although some typical trends may be noted. Protons $\mathrm{H}(2)$ and $\mathrm{H}(3)$ are slightly shifted to higher field by electron-donating groups $\mathrm{X}$, while $\mathrm{H}(4)$ remains nearly constant. Compared to $\mathrm{H}(4)$, the low-field shift of $\mathrm{H}(1)$ is quite surprising - giving a hint that the twist angle between the fulvene ring and the phenyl ring could be influenced by $x$.

$13_{\mathrm{C}}$ chemical shifts. ${ }^{13} \mathrm{C}$ chemical shifts are an ideal probe for the investigation of charge density effects in aromatic molecules of similar steric environment. For instance in monosubstituted benzenes, the observed chemical shifts of para-carbons correlate well with the total charge density calculated by $\mathrm{CNDO} / 2$, and good correlations between $\mathrm{p}$ - and m-carbons and Hammett $\sigma_{p}^{+}$constants are obtained (ref. 51).

In fact ${ }^{13} \mathrm{C}$ chemical shifts of $\mathrm{p}$-X-phenyl-pentafulvenes $2 \mathrm{~A}$ are systematically influenced by substituents $X$, and plots of $\sigma^{+}$versus $13 \mathrm{C}$ chemical shifts give linear correlations for $C(1)$ to $C(6)$ (ref. 50). As expected, electron releasing substituents $\mathrm{X}$ induce a high-field shift of the ring C-atoms which strongly decreases in the series $C(5)>C(2) / C(3)>C(1) / C(4)$. For $C(1)$ and $C(4)$ the changes are within experimental error. The only surprising feature is the linear low-field shift of $\mathrm{C}(6)$, which is reasonably explained if the twist angle between the two rings is influenced by the substituent $\mathrm{x}$.

Similar behaviour is observed for 6,6-disubstituted pentafulvenes 2B and 2C (Fig. 2). Electron-donating substituents $\mathrm{X}$ induce a high-field shift which decreases from $C(5)$ to $C(2) / C(3)$ to $C(1) / C(4)$. Fairly good linear correlations are obtained for $C(2) / C(3)$ and $C(1) / C(4)$ of sterically similar pentafulvenes $2 \mathrm{~B}$. Pentafulvenes of type $\underline{2 \mathrm{C}}$ show the same trends but with more scattering (open circles).

These results show that systematic electronic substituent effects influence $13 \mathrm{C}$ chemical shifts. Since plots of $\sigma^{+}$versus ${ }^{13} \mathrm{C}$ chemical shifts give linear correlations for both type $\underline{2 A}$ and $2 \mathrm{~B}$ pentafulvenes, the observed changes in chemical shifts may be attributed to changes in charge density.

Vicinal proton coupling constants. It is well known that vicinal $\mathrm{H}, \mathrm{H}$ coupling constants are strongly influenced by a) the dihedral angle, b) the ring size, c) the electronegativity of substituents and d) changes in bond lengths (ref. 52). As factors a) through c) are small or constant, the size of vicinal proton coupling constants $\mathrm{J}_{1}, 2, \mathrm{~J}_{2}, 3$ and $\mathrm{J}_{3,4}$ should reflect the electronic influence of substituents on bond lengths of the fulvene ring.

In fact, linear correlations between Hammett constants $\sigma_{p}^{+}$and vicinal proton coupling constants are obtained for 6 ( $\mathrm{p}-\mathrm{X}$-phenyl) pentafulvenes $2 \mathrm{~A}$ (ref. 50). With increasing electron donating capacity of the substituent $\mathrm{x}, \mathrm{J}_{1,2}$ and $\mathrm{J}_{3,4}$ decrease, while $\mathrm{J}_{2,3}$ increases. This is exactly the trend expected for an increasing $\pi$-delocalisation in the five membered ring.

Similar results are obtained for 6,6-disubstituted pentafulvenes 2B (Fig. 3): with increasing electron-donating capacity of $\mathrm{x}, \mathrm{J}_{1,2}$ decreases while $\mathrm{J}_{2,3}$ increases. Compared to fulvenes $2 \mathrm{~A}$ the only difference is that (as expected) electronic effects are larger for pentafulvenes $2 \mathrm{~B}$, while deviation from the average slope of Fig. 3 is more pronounced for pentafulvenes $2 \mathrm{C}$ (open circles). If steric effects are minimised (by bridging of the exocyclic substituents $2 \mathrm{C} \rightarrow 2 \mathrm{~B}$ ) improved linear correlations are obtained. 


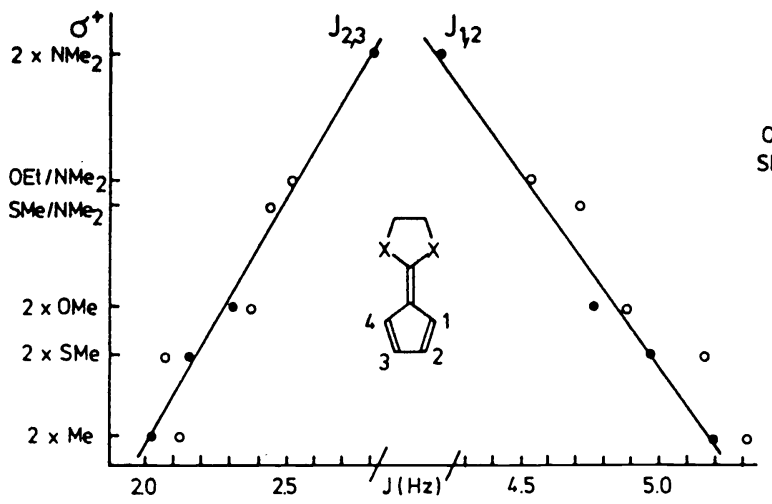

Fig. 3. Substituent effects on vicinal $\mathrm{H}, \mathrm{H}$ coupling constants of pentafulvenes $\underline{2 B}$ and $\underline{2 C}$ (open circles).

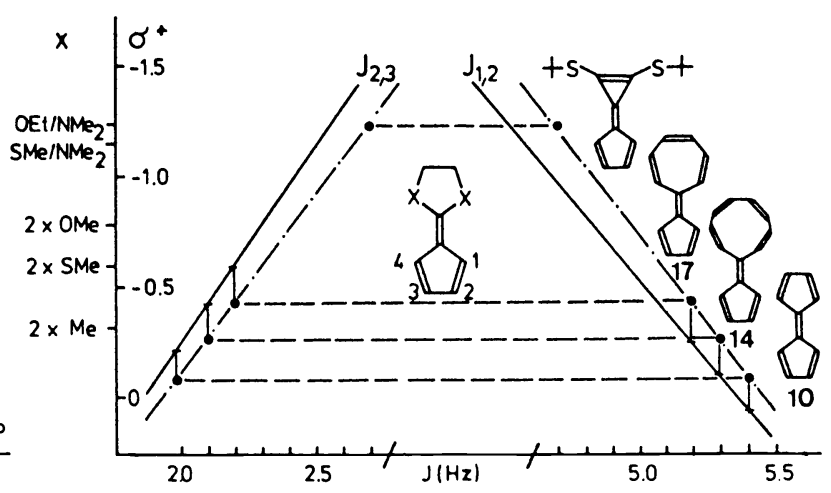

Fig. 4. Vicinal $\mathrm{H}, \mathrm{H}$ coupling constants of pentafulvalenes compared to substituent induced slopes of pentafulvenes $\underline{2 B}$.

These results show that systematic substituent effects influencing bond lengths may be observed in terms of relative changes of vicinal coupling constants, provided that steric effects are small. This means that in these systems the extent of $\pi$-delocalisation is accessible via vicinal coupling constants.

A serious test for this type of correlation (Fig. 3) could be provided by systems where only small changes in charge density and $\pi$-delocalisation may be expected. This situation is typical for the parent pentafulvalenes 10,14 and 17 prepared by our group. Figure 4 contains the substituent induced slopes of $\mathrm{J}_{1,2}$ and $\mathrm{J}_{2,3}$ of $\mathrm{Fig}$. 3. In this diagram vicinal $\mathrm{H}, \mathrm{H}$ coupling constants of pentafulvalenes, as calculated by analysis of the AA'XX'-type spectra, are entered. Averaging the obtained intersections to the best horizontal line gives the black circles. According to Fig 4, pentafulvalenes 10, 14 and 17 show the same substituent-induced slopes of vicinal $\mathrm{H}, \mathrm{H}$ coupling constants as pentafulvenes $2 \mathrm{~B}$; but there seems to be a small but systematic difference between both slopes of at about $\overline{0.1} \mathrm{~Hz}$. Obviously, the difference between vicinal $\mathrm{H}, \mathrm{H}$ coupling constants $\mathrm{J}_{1,2}$ and $\mathrm{J}_{2,3}$ is most pronounced for parent pentafulvalene 10 , and it slightly decreases from 10 to 14 and 17 . That means that $\pi$-delocalisation is very small for parent pentafulvalene $\overline{10}$, and it slightly increases from pentafulvalene 10 to nonapentafulvalene 14 and heptapentafulvalene 17 . While 10 is definitely more 10calised than 6,6-dimethyl-pentafulvene, 17 is somewhat more delocalised.

Instead of the still unknown calicene, we entered the coupling constants of the electronically only weakly disturbed 5,6-di(t-butylthio)calicene (ref. 53) as well as of 1-formyl5,6-di-n-propyl-calicene (ref. 54). Since both sets of coupling constants fitted perfectly with the pentafulvalene slopes of Fig. 4, this allowed us to mark the intersection of the two slopes which gives $\mathrm{J}_{1,2}=\mathrm{J}_{2,3}=3.67 \mathrm{~Hz}$ for a complete $\pi$-delocalisation. It is interesting to note that Yoshida reported $\mathrm{J}=3.66 \mathrm{~Hz}$ for cyclic dicalicene 45 , which seems to be fully delocalised according to X-ray data (ref. 55).

Diagrams like Fig. 4 are very useful for estimating the extent of delocalisation (or aromaticity) of molecules located between fully delocalised compounds such as $\underline{45}$ (aromaticity of $100 \%$ ) and pentafulvalene 10 (aromaticity of $0 \%$ ). According to that scale, heptapentafulvalene 17 has only $12 \%$ aromatic character, while 5,6-di-t-butylthio-calicene has an aromaticity of about $40 \%$.<smiles>CN(C)C(=C1CCCCC1)N(C)C</smiles>

$4 k$<smiles>CN(C)C(=C1C=CC2C=CC2C=C1)N(C)C</smiles>

46

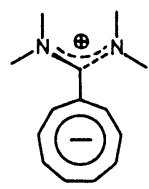

$4 k^{ \pm}$

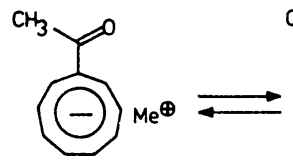

$26^{ \pm}$

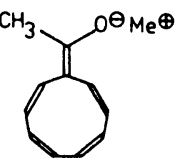

26

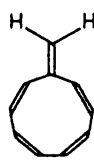

$4 a$

\section{NMR spectra of nonafulvenes}

After synthesising the first non-annelated nonafulvene (ref. 31), Hafner and Tappe discovered that 10,10-bis (dimethylamino) nonafulvene $4 \mathrm{k}$ displayed a rather spectacular NMR-spectroscopic behaviour: while the signals of ring protons of $4 \mathrm{k}$ were centered in the olefinic range at ambient temperature and/or in unpolar solvents, they experienced a pronounced low-field shift in polar solvents or at low temperature. In order to explain these results, Hafner proposed an equilibrium between the planar nonafulvene $4 \mathrm{k}$ (responsible for the low-field signals) and 
its bicyclic valence isomer 46 (ref. 56). In the light of new $220 \mathrm{MHz}$ experiments, where pairs of ring protons have been assigned and approximate $3 \mathrm{~J}$ coupling constants have been estimated, Tappe (ref. 57) discussed an equilibrium between 2 conformers: "the more planar one being favoured in polar solvents and/or at low temperature, the less planar conformer existing in unpolar solvents at higher temperature". Since then, similar dramatic effects have been observed by Boche and co-workers for acyl-cyclononatetraenides (ref. 58). These have been attributed to an equilibrium between the nonafulvenolate 26 existing as contact ion pair, and the solvent-separated ion pair $26 \pm$ existing in polar solvents and at low temperature. Subsequently, Boche suggested a similar equilibrium between the olefinic nonafulvene $4 \mathrm{k}$ and the corresponding formamidinium cyclononatetraenide $\underline{4 k} \pm$ (refs. 35,58 ).

However, the UV and NMR spectra of the electronically undisturbed parent system $4 \mathrm{a}$ are neither affected by solvents nor temperature and are compatible with a non-planar all-cis configurated ring system (ref. 6). Due to the fact that pairs of ring protons and ring C-atoms are equivalent at -1000 , a relatively fast process consisting of a switch of the exocyclic double bond has been proposed, by which two enantiomeric conformers equilibrate.

In order to explain the surprisingly different spectroscopic behaviour of nonafulvenes $4 \mathrm{a}$ and $\underline{4 k}, 1_{\mathrm{H}}$ and $13 \mathrm{C}$ NMR spectra of nonafulvenes $\underline{4 \mathrm{a}}-\underline{4 \mathrm{k}}$, including 10-dimethylamino-nonafulvene $\underline{4 l}$ (ref. 33), have been analysed (ref. 59). The experimental high-resolution proton NMR spectrum of $4 l$ is shown in Fig. 5 (upper trace). Spectra of that quality are only obtained in degassed solvents of low viscosity such as $\mathrm{CD}_{2} \mathrm{Cl}_{2}$ and $\mathrm{d}_{6}$-acetone or by resolution enhancement. Analysis by simulation and iteration of the nine subsystems gives the chemical shifts and 27 coupling constants different from zero. The calculated lower trace demonstrates a very good fit. All the chemical shifts of $4 l$ are in the olefinic range, and there is no dependence on solvent polarity or temperature - consequently, 10-dimethylamino-nonafulvene $\underline{4 l}$ is an olefinic molecule.

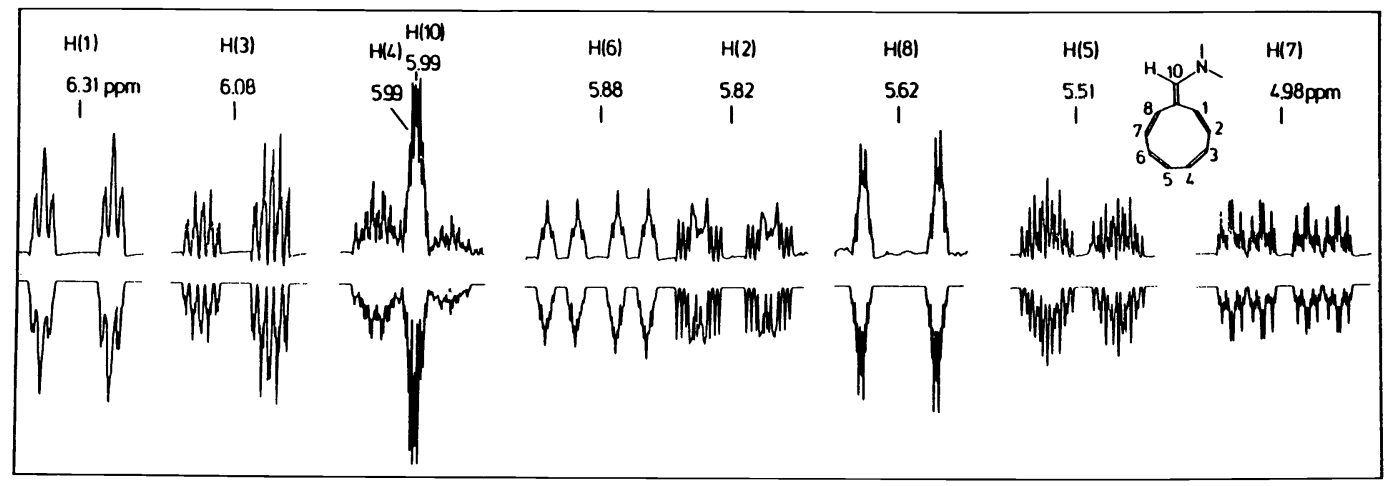

Fig. 5. $\mathrm{l}_{\mathrm{H}} \mathrm{NMR}$ spectrum of 10-dimethylamino-nonafulvene $4 \mathrm{e}\left(400 \mathrm{MHz}, \mathrm{CD}_{2} \mathrm{Cl}_{2},-10^{\circ}\right)$. Upper trace: experimental spectrum, lower trace: Calculated spectrum with the final set of $\delta-$ and J-values.
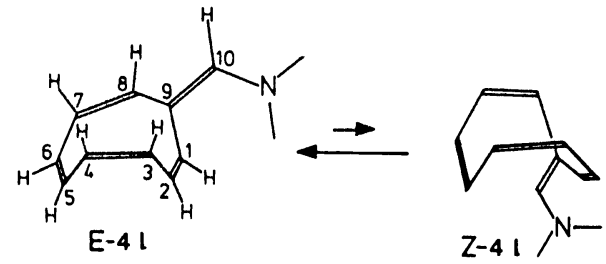

$\begin{array}{ll}J_{1,2}=12.00 & J_{5,6}=12.28 \\ J_{2,3}=2.73 & J_{6,7}=5.27 \\ J_{3,4}=11.82 & J_{7,8}=13.05 \\ J_{4,5}=3.03 & J_{1,4}=0.31\end{array}$

$\mathrm{J}_{25}=2.21$

$J_{3,6}=0.40$

$J_{4,7}=2.03$

E-4

Z-4 I

$J_{5,8}=0.82$

The NMR analysis of 4 e shows that olefinic $3 \mathrm{~J}$ couplings are large for cis-couplings, while couplings over formal single bonds are very small; this indicates that the nine membered ring of $\underline{4} \mathrm{l}$ is not planar. Furthermore, $\mathrm{J}_{6,7}$ is nearly twice as large as $\mathrm{J}_{2,3}$ and $\mathrm{J}_{4,5}$. Bearing in mind the well known Karplus equation, the conclusion is that the dihedral angle between protons $H(6)$ and $H(7)$ is small compared with dihedral angles of protons $H(2)$ and $H(3)$ or $H(4)$ and $\mathrm{H}(5)$. Examination of Dreiding molecular models shows that this is the case if the fulvene contains a nearly planar E-configurated dienamine unit consisting of atoms $N-C(10)-C(9)-C(8)-$ $C(7)$. As a consequence, the $C(6)-C(7)$ bond shows a medium deviation out of the plane of the dienamine unit while double bonds $C(1)=C(2)$ and $C(3)=C(4)$ are located strongly out of plane. This conclusion is supported by the comparably large $5 \mathrm{~J}$ couplings $\mathrm{J}_{2,5}$ and $\mathrm{J}_{4,7}$. Finally, conformation E- $\underline{4 l}$ is favoured over conformation $\mathrm{Z}-\underline{4 l}$ due to steric reasons.

Investigations of 10-monosubstituted nonafulvenes favour a predominant E-4 conformation as well (ref. 59). With increasing electron-donating capacity of the substituent (in the series $\underline{4 \mathrm{C}} \longrightarrow \underline{4 \mathrm{f}} \longrightarrow \underline{4 \ell}$ ) proton chemical shifts are not strongly affected with exception of $\mathrm{H}(7)$. Furthermore, considerable high field shifts are observed in the $13 \mathrm{C}$ NMR for $\mathrm{C}(9)>\mathrm{C}(7)>\mathrm{C}(5)$. 


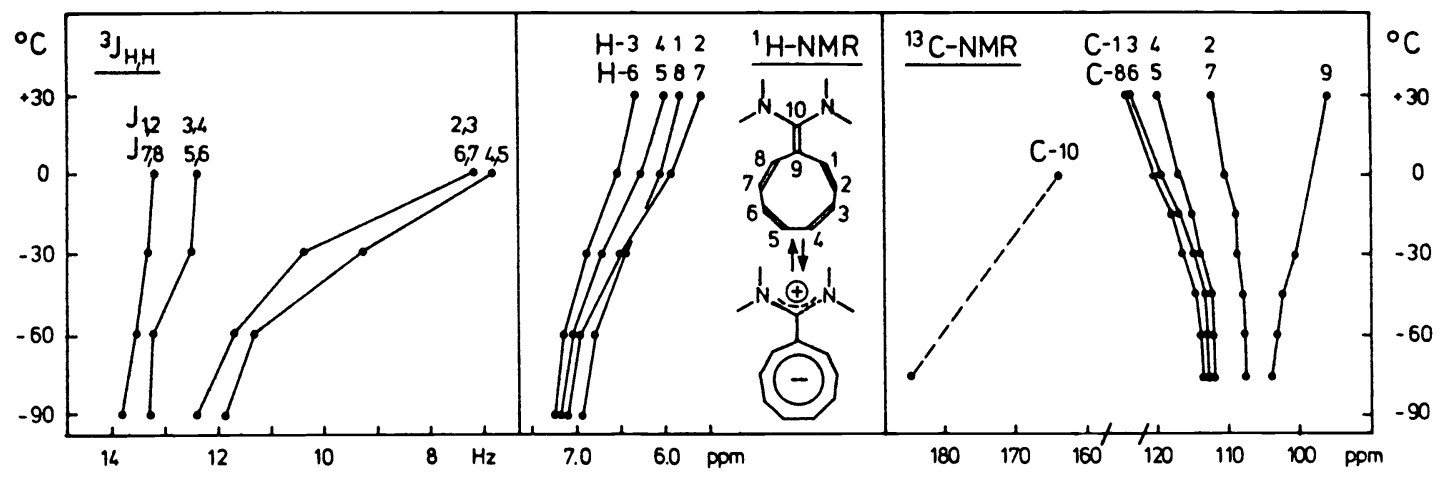

Fig. 6. Influence of temperature on vicinal proton coupling constants $/ 1_{\mathrm{H}}$ chemical shifts / ${ }^{13} \mathrm{C}$ chemical shifts of $\underline{4 \mathrm{k}}$ (BRUKER $\mathrm{AM} 400, \mathrm{CD}_{2} \mathrm{Cl}_{2}$ ).

If we look at the influence of solvent and temperature on NMR parameters, three classes of nonafulvenes may be distinguished. Most nonafulvenes (type A nonafulvenes) show neither influence of solvent polarity nor temperature in the range between $\mathrm{CD}_{2} \mathrm{Cl}_{2}$ and $\mathrm{d}_{6}$-acetone or between $+20^{\circ}$ and $-90^{\circ}$ respectively. With increasing electron donating capacity of the substituents an interesting borderline is reached in the case of 10-methylthio-lo-dimethylaminononafulvene 4 i (type B nonafulvene). As for type A nonafulvenes, no influence of solvent or temperature is effective on $l_{\mathrm{H}}$ and $13 \mathrm{C}$ chemical shifts. However, in the NMR spectra of $4 i$, protons and ring C-atoms are equivalent up to $-60^{\circ}$, and splitting of ${ }^{13} \mathrm{C}$ signals takes place at very low temperature. This means that rotation around the exocyclic double bond is fast enough at ambient temperature. Finally, very strong influences of solvent polarity and temperature on spectral parameters are observed for 10,10-bis (dimethylamino) nonafulvene $4 \mathrm{k}$ (ref. 31) as an exponent of type C nonafulvenes bearing two strongly electron donating substituents. Some results of a detailed investigation of temperature effects on spectral parameters (ref. 59) completing previous work of Hafner and Tappe (refs. 31, 57). are summarised in Fig. 6.

Lowering the temperature of $\mathrm{CD}_{2} \mathrm{Cl}_{2}$ solutions of nonafulvene $4 \mathrm{k}$ has a dramatic effect on coupling constants over formal single bonds which approach couplings over formal double bonds at $-90^{\circ}$ (Fig. 6, left section). This is best explained by a substantial ring flattening due to an increase in $\pi$-delocalisation. Furthermore, a decrease in temperature results in a lowfield shift of all the ring protons of $4 \mathrm{k}$ which is most pronounced for $\mathrm{H}(2)$ and $\mathrm{H}(7)$ (Fig. 6 , medium section). This behaviour agrees with an increasing ring current which is counterbalanced to some extent by the opposite charge density effect. Finally, an increasing negative excess charge of the ring C-atoms is expected to induce a considerable high-field shift of ring C-atoms, which is, in fact, observed for C-atoms C(1) - C(8) (Fig. 6, right section). The effect is most pronounced for $C(1) / C(8)$ and $C(3) / C(6)$, it decreases in the series $C(4) / C(5)$ and $C(2) / C(7)$, and it is counterbalanced by another (probably steric) effect for $C(9)$. Summarising, the observed behaviour of $4 \mathrm{k}$ is best explained by Boche's proposition (ref. 58) which assumes an equilibrium between the non-planar nonafulvene $4 \mathrm{k}$ existing at high temperature and in unpolar solvents and the dipolar amidinium-cyclononatetraenide $\underline{4 \mathrm{k}^{ \pm}}$.

Looking at all the nonafulvenes prepared so far, three classes of nonafulvenes may be distinguished: type A nonafulvenes bearing substituents of comparably low electron releasing capacity exist in the nonplanar nonafulvene form. Activation energy for rotation around the exocyclic double bond is high, and solvent as well as temperature effects (mainly influencing

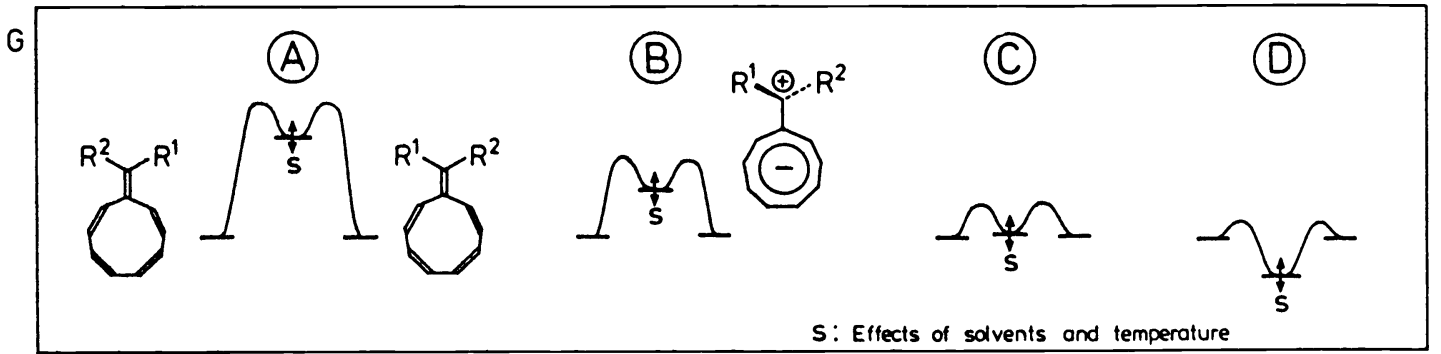

Fig. 7. Different types of nonafulvenes in dependence of the difference in free energy $\Delta G$ between the nonplanar nonafulvene $\underline{4}$ and the dipolar carbenium cyclononatetranide $\underline{4}^{ \pm}$ 
the entropy term) are too small to result in any population of the dipolar intermediate. For type B nonafulvenes, the activation energy for rotation around $C(9)=C(10)$ is small enough at ambient temperature due to a lower energy of the dipolar intermediate. However, $\Delta \mathrm{G}$ between $\underline{4}$ and $\underline{4}$ is still too high to allow a population of $\underline{4 k}$. Hafner's nonafulvene $\underline{4 k}$ is the exponent of type $\mathrm{C}$ nonafulvenes, in which the energy of the dipolar form $4 \mathrm{k}^{ \pm}$is $\overline{\mathrm{so}}$ near the levels of the nonplanar nonafulvene $\underline{4 k}$ that solvent or temperature effects may favour $4 \mathrm{k}$ or $4 \mathrm{k}^{ \pm}$. Finally, presently unknown type $\mathrm{D}$ nonafulvenes may be foreseen in which the dipolar form $\underline{4^{ \pm}}$is much lower in energy than the nonafulvene form.

\section{ACKNOWLEDGEMENT}

I would like to express my appreciation to the following collaborators who have contributed to this work: Dr. P. Bigler, P. Bönzli, A. Escher, J. Furrer, J. Krebs, Dr. R.W. Millar, Dr. A. Otter, Dr. W. Rutsch, Dr. G. Sabbioni, Dr. U. Stämpfli, Dr. A. Weber. Furthermore, financial support by the Swiss National Foundation is gratefully acknowledged.

\section{REFERENCES}

1. P. Yates, Advances in Alicyclic Chemistry, Vol. 2, p. 59, Academic Press, New York (1968); E.D. Bergmann, Chem. Rev. 68, 41 (1968); D. Lloyd, Non-benzenoid Conjugated Carbocyclic Compounds, Elsevier, Amsterdam (1984).

2. R. Hollenstein, W. von Philipsborn, R. Vögeli and M. Neuenschwander, Helv. Chim. Acta 56, 847 (1973).

3. J. Thiec and J. Wiemann, Bull. Soc. Chim. Fr. 23, 177 (1956); 27, 1066 (1960); E. Sturm and K. Hafner, Angew. Chem. 20, 862 (1964); H. Schaltegger, M. Neuenschwander and D. Meuche, Helv. Chim. Acta 48, 955 (1965).

4. W. von E. Doering and D.H. Wiley, Tetrahedron 11, 183 (1960); H.E. Zimmermann and L.R. Souza, J. Am. Chem. Soc. 94, 834 (1972); B.M. Trost, R.C. Atkins and L.L. Hoffmann, J. Am. Chem. Soc. 95, 1285 (1973).

5. M. Neuenschwander and W.K. Schenk, Chimia 26, 194 (1972); W.K. Schenk, R. Kyburz and M. Neuenschwander, Helv. Chim. Acta 58, 1099 (1975).

6. M. Neuenschwander and A. Frey, Chimia 28, 119 (1974); 29, 212 (1975).

7. P.A. Baron, R.D. Brown, F.R. Burden, J.J. Domaille and J.E. Kent, J. Mol. Spectrosc. 43, 401 (1972).

8. A. Bauder, C. Keller and M. Neuenschwander, J. Mol. Spectrosc. 63, 281 (1976).

9. W.E. Billups, L.-J. Lin and E.W. Casserley, J. Am. Chem. Soc. 106, 3698 (1984).

10. S.W. Staley and T.D. Norden, J. Am. Chem. Soc. 106, 3699 (1984).

11. B. Uebersax, M. Neuenschwander and H.-P. Kellerhals, Helv. Chim. Acta 65,74 (1982).

12. W. von E. Doering and H. Krauch, Angew. Chem. 68, 661 (1956); D.W. Wiley, Ph.D., Yale University (1954); W.M. Jones and C.L. Ennis, J. Am. Chem. Soc. 89, $3069 \overline{(1967) ; 91,6391}$ (1969); K. Kato, Y. Kitahara, N. Morita and T. Asao, Chem. Lett. 873 (1977).

13. W.K. Schenk, R. Kyburz and M. Neuenschwander, Helv. Chim. Acta 58, 1099 (1975); H. Babsch and H. Prinzbach, Tetrahedron Lett. 645 (1978); see also: H. Prinzbach and W. Rosswog, Angew. Chem. 73, 543 (1961).

14. W. von E. Doering, Kekulé Symposium, Butterworth, London (1959), E.A. Matzner, Ph.D., Yale University (1958).

15. R. Brand, H.-P. Krimmer, H.-J. Lindner, V. Sturm and K. Hafner, Tetrahedron Lett. 5131 (1982).

16. A.S. Kende, P.T. Izzo and P.T. MacGregor, J. Am. Chem. Soc. 88, 3359 (1966); H. Prinzbach and E. Woischnik, Helv. Chim. Acta 52, 2472 (1969).

17. H. Prinzbach, Pure Appl. Chem. 28, 281 (1981).

18. Z. Yoshida, Pure Appl. Chem. 54, 1059 (1982).

19. P.J. Garratt and K.A. Knapp, J. Chem. Soc. Chem. Commun. 1084 (1971).

20. M. Rabinovitz and A. Gazit, J. Chem. Res. (S) 438 (1978); (M) 5151 (1978).

21. W. von E. Doering and H. Krauch, Angew. Chem. 68, 661 (1956); A.G. Anastassiou, J. Chem. Soc. Chem. Commun. 913 (1972).

22. E.D. Bergmann and I. Agranat, J. Am. Chem. Soc. 86, 3587 (1964); A.S. Kende and P.T. Izzo, J. Am. Chem. Soc. 86, 3587 (1964); W.M. Jones and J.M. Denham, J. Am. Chem. Soc. 86, 944 (1964).

23. M. Neuenschwander and W.K. Schenk, Chimia 29, 215 (1975).

24. A. Weber and M. Neuenschwander, Angew. Chem. 93, 788 (1981).

25. C.w. Jefford, M. Acar, A. Delay, J. Mareda and U. Burger, Tetrahedron Lett. 1913 (1979).

26. J. Krebs and M. Neuenschwander, unpublished results.

27. T.J. Katz and P.J. Garratt, J. Am. Chem. Soc. 85, 2852 (1963); 86, 5194 (1964).

28. E.A. LaLancette and R.E. Benson, J. Am. Chem. SoC. 85, 2853 (1963); 87, 1941 (1965). 
29. G. Boche, D. Martens and W. Danzer, Angew. Chem. 81, 1003 (1969); G. Boche, H. Weber, D. Martens and A. Bieberbach, Chem. Ber. 1ll, 2480 (1978).

30. G. Boche and A. Bieberbach, Tetrahedron Lett. 1021 (1976); Chem. Ber. 111,2850 (1978).

31. K. Hafner and H. Tappe, Angew. Chem. 81, 564 (1969).

32. G. Boche and F. Heidenhain, Angew. Chem. 90, 290 (1978).

33. G. Boche, F. Heidenhain and B. Staudigl, Tetrahedron Lett. 4201 (1979); Chem. Ber. 115, 3191 (1982).

34. G. Sabbioni and M. Neuenschwander, Helv. Chim. Acta 68, 623 (1985); 68, 887 (1985);

G. Sabbioni, A. Otter, R.W. Millar and M. Neuenschwander, Helv. Chim. Acta 68, in press;

G. Sabbioni, Dissertation, University of Bern (1982).

35. G. Boche, M. Bernheim, D. Lewaldt and B. Ruisinger, Tetrahedron Lett. 4285 (1979).

36. R. Kyburz, H. Schaltegger and M. Neuenschwander, Helv. Chim. Acta 54, 1037 (1971);

M. Neuenschwander and R. Iseli, Helv. Chim. Acta 60, 1061 (1977).

37. M. Neuenschwander, W. Rutsch and P. Engel, Tetrahedron Lett. 233 (1979); w. Rutsch,

A. Frey and M. Neuenschwander, Helv. Chim. Acta 62, 718 (1979).

38. A. Otter, Dissertation, University of Bern (1984).

39. W. Rutsch, Dissertation, University of Bern (1978).

40. E. Maréchal, J.-J. Basselier and P. Siegwalt, Bull. Soc. Chim. Fr. 1740 (1964).

41. K. Hafner, S. Braun, T. Nakazawa and H. Tappe. Tetrahedron Lett. 3507 (1975).

42. W. Rutsch, A. Escher and M. Neuenschwander, Chimia 37, 160 (1983).

43. U. Klinsmann, J. Gauthier, K. Schaffner, M. Pasternak and B. Fuchs, Helv. Chim. Acta 55 , 2643 (1972).

44. A. Escher and M. Neuenschwander, Angew. Chem. 96, 983 (1984).

45. A. Escher, P. Engel and M. Neuenschwander, unpublished results.

46. R. Hollenstein, A. Mooser, M. Neuenschwander and W. von Philipsborn, Angew. Chem. 86,595 (1974).

47. H.L. Ammon, Acta Crystallogr. Sect. B, 30, 1731 (1974); R. Böhme and H. Burzlaff, Chem. Ber. 107, 832 (1974).

48. H. Shimanouchi, Y. Sasada, Ch. Kabuto and Y. Kitahara, Acta Crystallogr. Sect. B, 30, 1267 (1974).

49. L. Knothe, H. Prinzbach and H. Fritz, Liebigs Ann. Chem. 687 (1977).

50. A. Otter, H. Mühle, M. Neuenschwander and H.P. Kellerhals, Helv. Chim. Acta 62, 1626 (1979); P. Bönzli, A. Otter, M. Neuenschwander and H.P. Kellerhals, Magn. Reson. in Chem., in preparation; see also: D.J. Sardella, C.M. Keane and P. Lemonias, J. Am. Chem. Soc. 106,4962 (1984).

51. G.L. Nelson, G.C. Levy and J.D. Cargioli, J. Am. Chem. Soc. 94, 3089 (1972); E.M. Schulmann, K.A. Christensen, D.M. Grant and C. Walling, J. Org. Chem. 39, 2668 (1974).

52. H. Günther, NMR-Spektroskopie, Thieme, Stuttgart (1983).

53. Z. Yoshida, M. Shibata, S. Kida, S. Miki, T. Sugimoto and S. Yoneda, Tetrahedron Lett. 345 (1984).

54. A.S. Kende, P.T. Izzo and P.T. MacGregor, J. Am. Chem. Soc. 88, 3359 (1966).

55. S. Yoneda, M. Shibata, S. Kida, Z. Yoshida, K. Miki and N. Kasai, Angew. Chem. 96,75 (1984).

56. K. Hafner, Aromaticity, Pseudo-Aromaticity and Anti-Aromaticity, p. 256, The Israel Academy of Sciences, Jerusalem (1971).

57. H. Tappe, Dissertation, Technische Hochschule Darmstadt (1972).

58. G. Boche and F. Heidenhain, J. Am. Chem. Soc. 101, 738 (1979); G. Boche, F. Heidenhain, W. Thiel and R. Eiben, Chem. Ber. 115, 3167 (1982).

59. A. Otter, M. Neuenschwander and H.P. Kellerhals, Magn. Reson. in Chem., in preparation; A. Otter, G. Sabbioni, M. Neuenschwander and H.P. Kellerhals, Magn. Reson. in Chem., in preparation. 